\title{
Preliminary Investigations on Double Sided Incremental Forming of Thermoplastics
}

\author{
Mohammad Ali Davarpanah ${ }^{\mathrm{a}}$, Zixuan Zhang ${ }^{\mathrm{b}}$, Shalu Bansal ${ }^{\mathrm{a}}$, Jian Cao ${ }^{\mathrm{b}}$, Rajiv Malhotra ${ }^{\mathrm{a}^{*}}$ \\ ${ }^{a}$ Department of Mechanical Engineering, Oregon State University, Corvallis, Oregon-97331, \\ United States \\ b Department of Mechanical Engineering, Northwestern University, Evanston, Illinois- 60208- \\ 3111, United States
}

\begin{abstract}
Single Point Incremental Forming (SPIF) of polymers has gained significant attention due to the high material formability, absence of external heating of the polymer, and the use of part-shapeindependent tooling. Despite the advantages of Double Sided Incremental Forming (DSIF) of metals, polymer DSIF has not yet been explored. This study examines DSIF of a PVC polymer. Forming forces, formability and void structure of the formed polymer in SPIF and DSIF are compared. Significant advantages of polymer DSIF over SPIF are observed including greater formability, reduced void growth in the material and reduced sheet bending outside the desired forming region.
\end{abstract}

Keywords: Double Sided Incremental Forming, Polymers, Formability, Forces, Void area fraction

\section{Introduction}

Single Point Incremental Forming (SPIF) locally deforms a fully peripherally clamped sheet using a small hemispherical ended tool moving along a pre-defined 3D toolpath [1-4]. Double Sided Incremental Forming (DSIF) uses one such tool on either side of the sheet, such that one tool forms the sheet and the other tool supports or squeezes the sheet locally. Past work on DSIF of metals [5-8] has shown significant advantages over SPIF, including higher formability and improved geometric accuracy. SPIF of commodity and engineering thermoplastics including PVC, PLA, Polyamide, PET, PC and POM has been demonstrated [915], without the need for any external heating of the polymer. Currently, thermoplastic surfaces for prototyping and replacement in automobile interiors, low volume fabrication in aircraft interiors [16] and packaging are typically fabricated via injection molding or hot forming. The reduced cost of thermal energy and tooling in polymer incremental forming can reduce the manufacturing costs in these applications. Furthermore, thermoplastics are more amenable to meeting fire safety standards in the automotive and aerospace industries than thermosets [17]. Despite the above advantages of DSIF, polymer DSIF has not yet been explored. This paper

*Corresponding Author. Email: malhotra@oregonstate.edu 
reports preliminary experimental work performed to explore the feasibility of polymer DSIF. SPIF, Conventional DSIF (CDSIF) and Accumulative DSIF (ADSIF, [8]) of commercially obtained PVC are compared in terms of key process and material indexes including forming forces, formability and void content of the formed polymer. These indexes are characterized in terms of the incremental depth $(\Delta z)$, i.e., the step down in the part depth direction in each consecutive pass of the tool [1], the squeeze factor (s), i.e., the amount by which the two tools squeeze the sheet [18], and the part shape. The feasibility and advantages of polymer DSIF over SPIF are demonstrated and future research directions for polymer DSIF are discussed.

\section{Experiments}

A DSIF machine [5, 6, 8] with a forming area of $250 \times 250 \mathrm{~mm}^{2}$, and two tool-mounted load cells for measuring forming forces, was used to form $1.6 \mathrm{~mm}$ thick PVC sheets with $10 \mathrm{~mm}$ diameter tools. A PTFE based grease was used as the lubricant at the tool-sheet interface with a tool feed rate of $10 \mathrm{~mm} / \mathrm{sec}$. A $60^{\circ}$ wall angle cone and a funnel shape, with radius of curvature $R_{f}$ of $80 \mathrm{~mm}$ and $150 \mathrm{~mm}$ and continuously changing wall angle from $30^{\circ}$ to $90^{\circ}$ (Fig. 1a), were formed with CDSIF using $\Delta z=1.2 \mathrm{~mm}$ and $1.8 \mathrm{~mm}$. Squeeze factors $s$ of 0.8 and 1.0 were investigated. Note that when $s=1.0$ the bottom tool is just touching the sheet and when $s<1.0$, the tools are actively squeezing the sheet in the local deformation region between the two tools [5]. SPIF and ADSIF of the cone shape were also performed using $\Delta z=1.8 \mathrm{~mm}$. In CDSIF and ADSIF, the bottom tool was positioned based on the sine law [5]. All experiments were performed using a spiral toolpath (Fig. 1b, [1]).

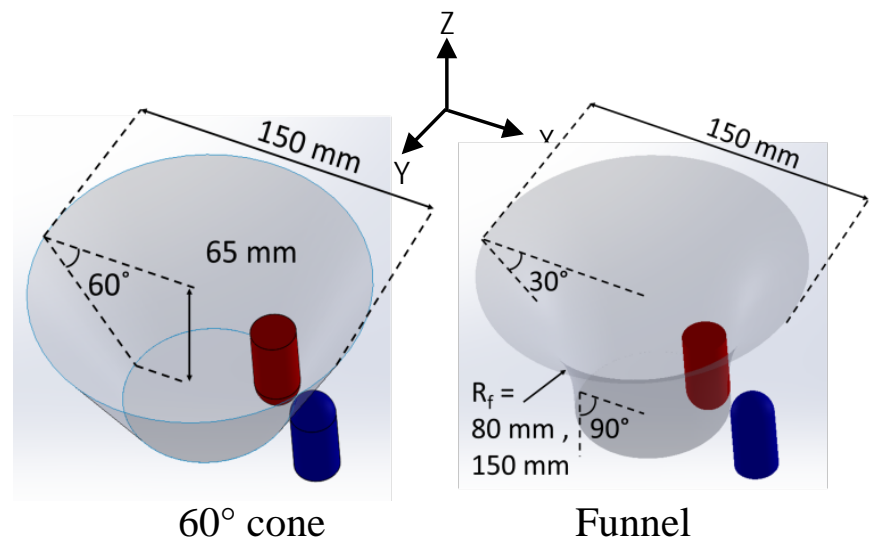

(a)

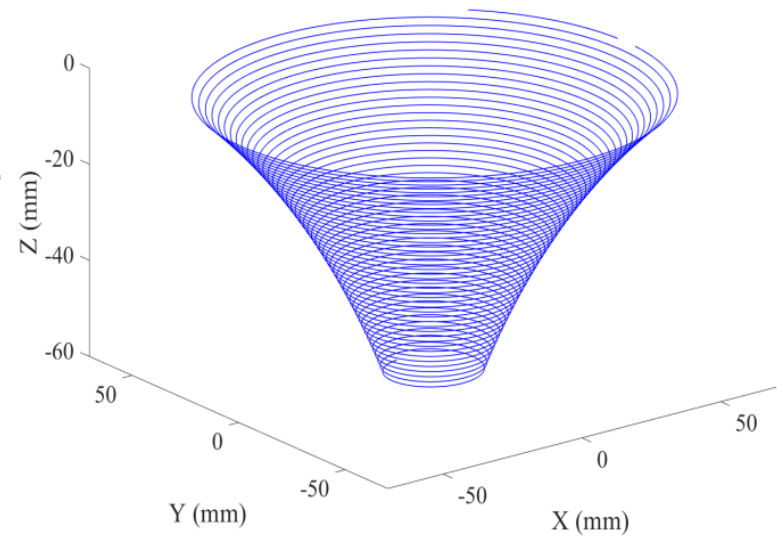

(b)

Fig. 1: (a) Schematic of formed cone and funnel parts (b) Representative example of spiral toolpath used, shown here for a funnel shape

\section{Results}

Figures 2a-2e show parts formed with SPIF, CDSIF and ADSIF. The fracture depth and wall angle are commonly used to describe the formability in incremental forming. At the same $\Delta z$ (Table 1) the formed depth of the cone is greater with CDSIF (Fig. 2b) and ADSIF (Fig. 2c) 
than with SPIF (Fig. 2a), indicating greater formability with DSIF. In fact, no sheet failure is observed with ADSIF. Furthermore, in CDSIF a reduction in $s$ (i.e., greater squeezing of the sheet) and an increase in $\Delta z$ increases the formability (Table 1). Greater formability with greater $\Delta z$ has also been observed in polymer SPIF [15], which is the opposite trend to that seen in metal SPIF. The formability also seems to depend on the overall part shape, as in polymer SPIF [15], since the funnel with $R_{f}=150 \mathrm{~mm}$ (Fig. 2e) is deformed to a greater wall angle than the funnel with $R_{f}=80 \mathrm{~mm}$ (Fig. 2d).

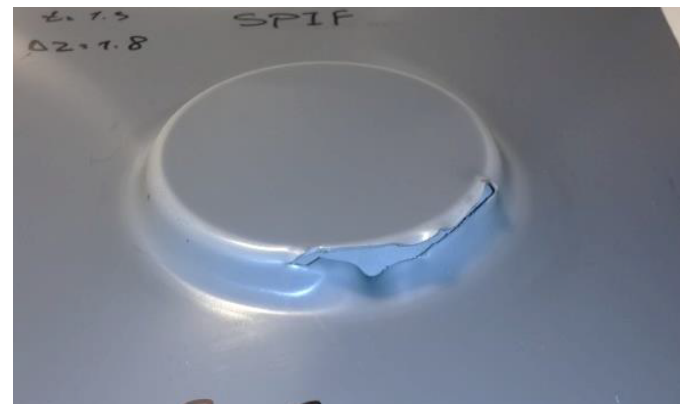

(a)

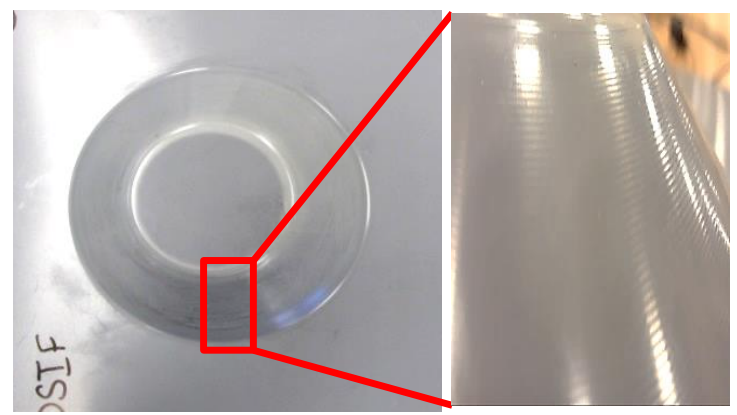

(c)

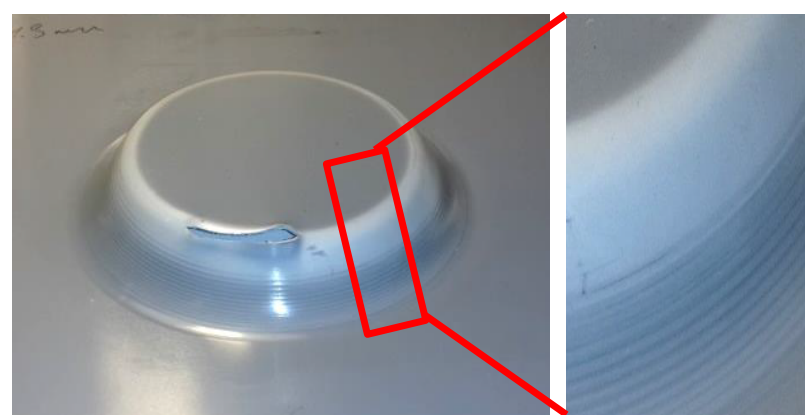

(b)

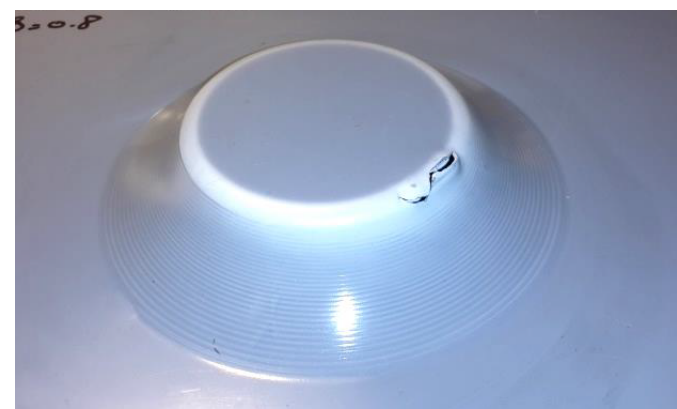

(d)

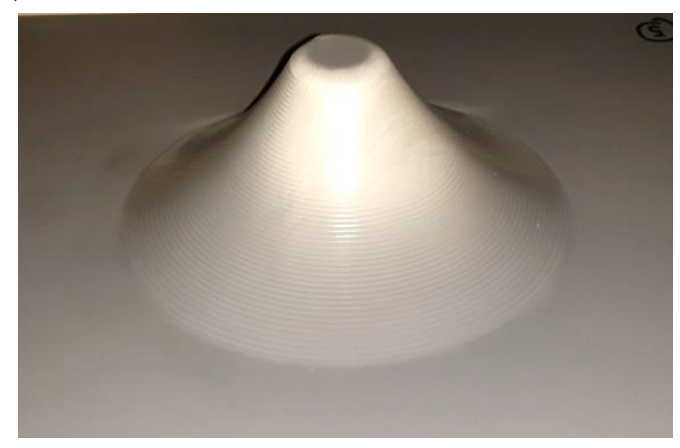

(e)

Fig. 2: Cone shape formed with (a) SPIF (b) CDSIF (c) ADSIF; (d) $R_{f}=80 \mathrm{~mm}$ funnel formed with CDSIF (e) $R_{f}=150 \mathrm{~mm}$ funnel formed with CDSIF. 
Table 1: Process parameters and tool tip depths at failure

\begin{tabular}{|c|c|c|c|c|}
\hline Part & Process & $\Delta \mathrm{z}(\mathrm{mm})$ & Squeeze factor & $\mathrm{Z}$ depth at failure $(\mathrm{mm})$ \\
\hline \multirow{6}{*}{$60^{\circ}$ Cone } & SPIF & 1.8 & Not applicable & 28.2 \\
\hline & \multirow{4}{*}{ CDSIF } & 1.8 & 1.0 & 34.1 \\
\hline & & 1.8 & 0.8 & 35.3 \\
\hline & & 1.2 & 1.0 & 28.2 \\
\hline & & 1.2 & 0.8 & 29.2 \\
\hline & ADSIF & 1.8 & 1.0 & No failure \\
\hline \multirow{4}{*}{$\begin{array}{l}\text { Funnel } \\
\left(R_{f}=80 \mathrm{~mm}\right)\end{array}$} & \multirow{4}{*}{ CDSIF } & 1.8 & 1.0 & $37.75\left(66.8^{\circ}\right.$ wall angle $)$ \\
\hline & & 1.8 & 0.8 & 41.44 (69.6 $6^{\circ}$ wall angle) \\
\hline & & 1.2 & 1.0 & 37.8 (66.1 $1^{\circ}$ wall angle), \\
\hline & & 1.2 & 0.8 & $38.0 \mathrm{~mm}\left(67.2^{\circ}\right.$ wall angle $)$ \\
\hline $\begin{array}{l}\text { Funnel } \\
\left(R_{f}=150 \mathrm{~mm}\right)\end{array}$ & CDSIF & 1.2 & 0.8 & $\begin{array}{l}\text { No failure observed, tool- } \\
\text { part interference at } 71.0^{\circ} \\
\text { wall angle prevented } \\
\text { continuation of forming }\end{array}$ \\
\hline
\end{tabular}

A closer observation of the side of the sheet in contact with the bottom tool (Fig. 2b) and of the forming forces (Fig. 3a) in CDSIF, shows a gradual loss of contact between the sheet and the bottom tool. This phenomenon is also seen in metal CDSIF [18, 19]. A concurrent change in the color of the sheet was observed, from grey when tool-sheet contact was retained to whitishgrey when tool-sheet contact was lost. This color change indicates the occurrence of crazing [9] after tool-sheet contact is lost in CDSIF, which typically leads to growth of larger voids and fracture. In ADSIF there is no loss of contact between the bottom tool and the sheet (Figs. 2c and $3 b)$ and no change in color of the polymer. This absence of crazing is probably the reason behind higher formability in ADSIF than in CDSIF. Figures 4a-e show representative SEM images of the outer surface of the formed parts, along with binary images (inset) obtained after image processing with ImageJ software. Multiple such images were analyzed to calculate the surface void area fraction in the formed material (Fig. 4f). The void area fraction is much higher for SPIF than for CDSIF in the region of the part where tool-sheet contact is retained. When contact is lost in CDSIF, the void area fraction rises to levels similar to those in SPIF. Since tool contact is not lost in ADSIF the void area fraction stays low. This observation further supports the hypothesis that retention of tool-sheet contact in ADSIF reduces crazing and resultant void growth in the polymer, resulting in greater formability with ADSIF as compared to CDSIF and SPIF. For the cone shape, the geometric definition of the interface between the wall of the formed part and the ideally flat part of the sheet was observed to be significantly improved with 
CDSIF and ADSIF than with SPIF (Figs. 2a-2c). This indicates a reduction in the unwanted bending of the sheet outside the desired deformation zone with DSIF. A similar degree of geometric definition can also be seen in CDSIF of the funnel shape (Figs. 2d-2e).

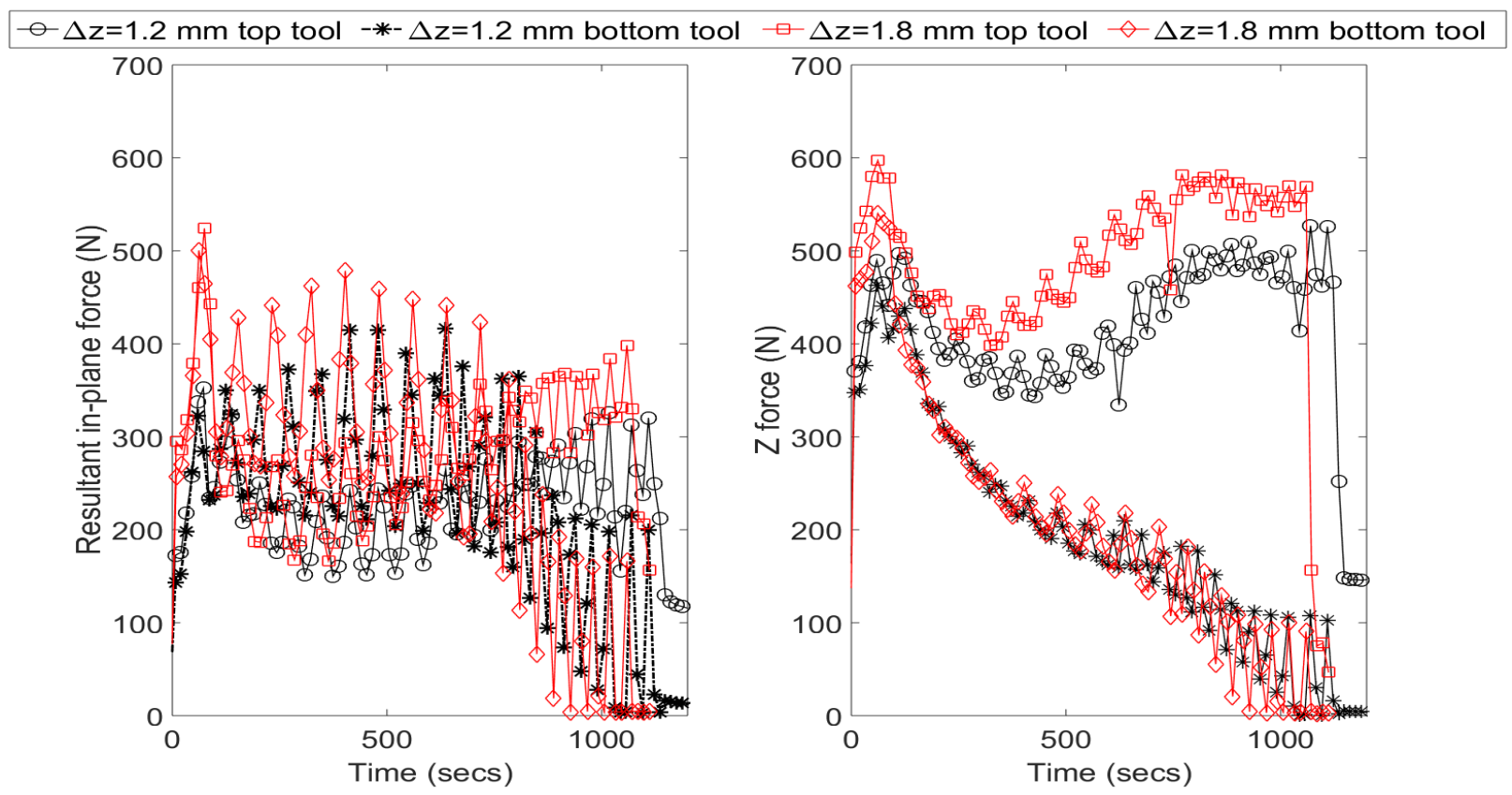

(a)

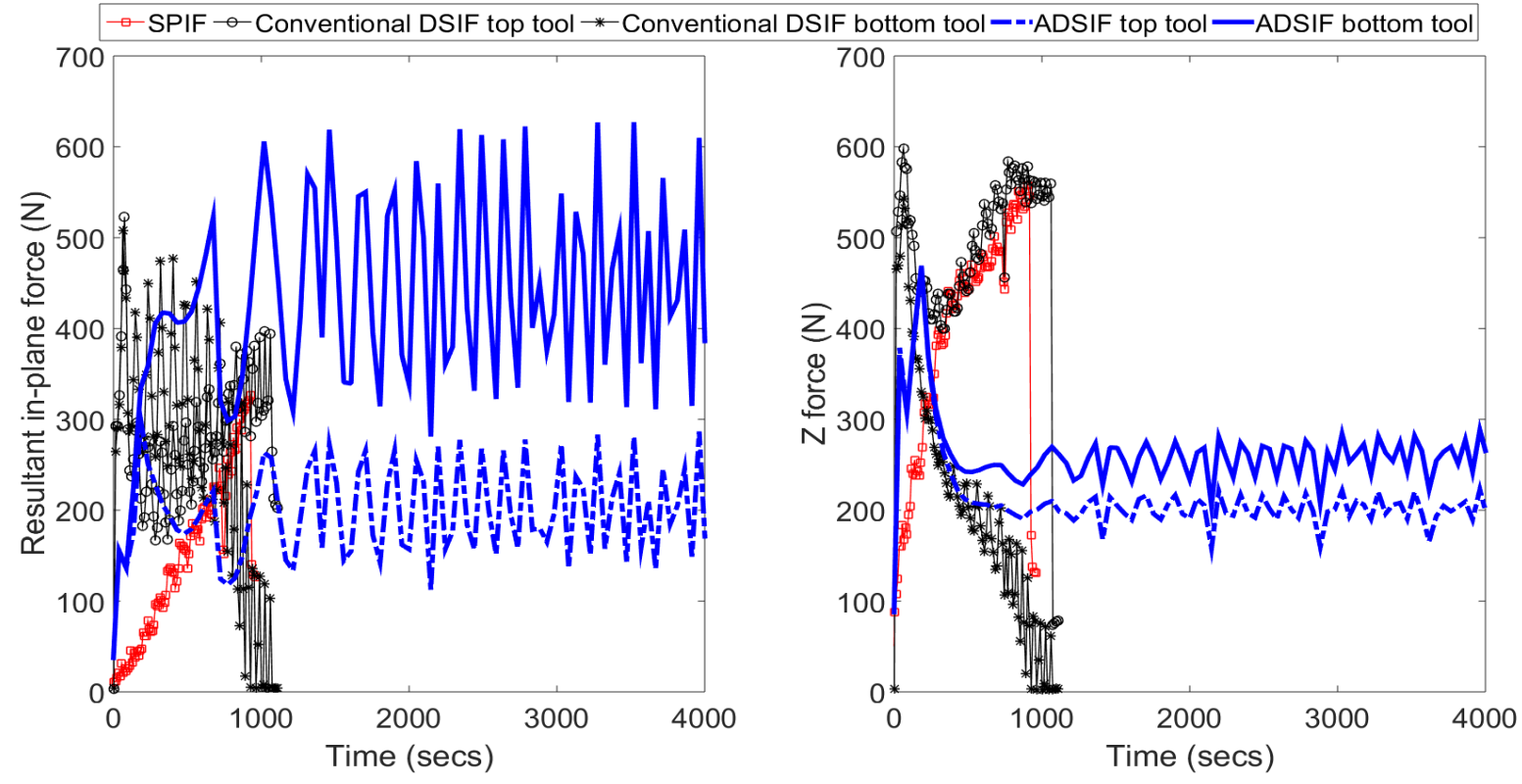

(b)

Fig. 3: Magnitude of forming forces for $60^{\circ}$ cone formed (a) by CDSIF with $\Delta z=1.2$ and $1.8 \mathrm{~mm}$ and $s=1.0$ (b) by SPIF, CDSIF and ADSIF with $\Delta z=1.8 \mathrm{~mm}$ and $s=1.0$. 


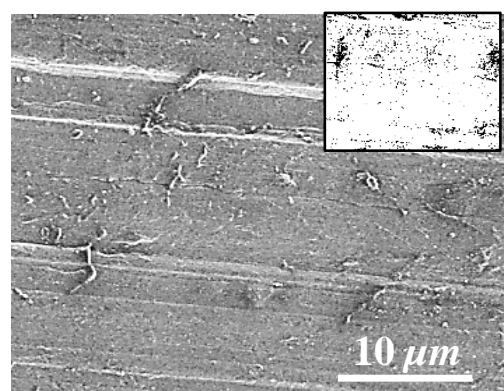

(a)

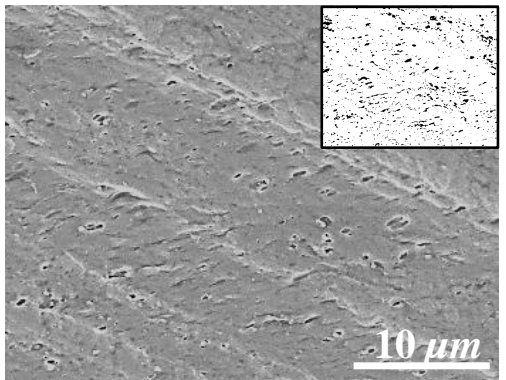

(b)

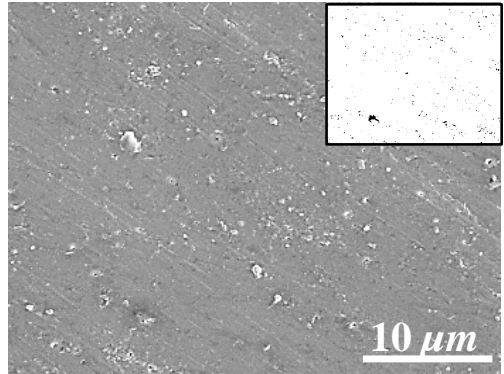

(c)

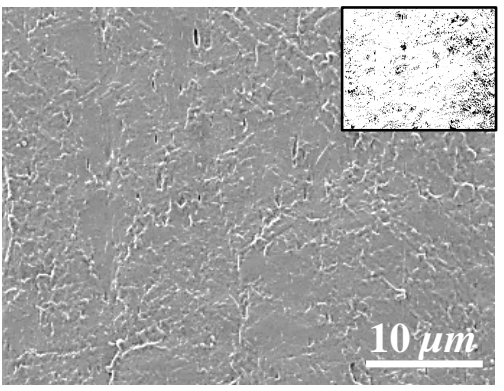

(d)

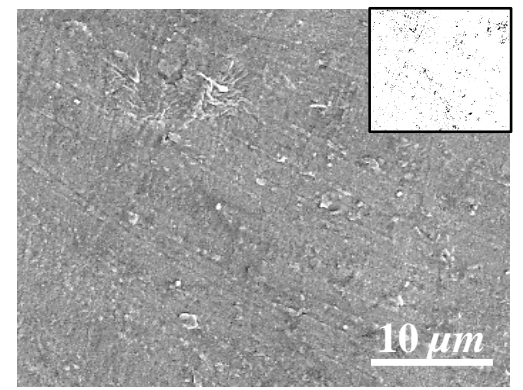

(e)

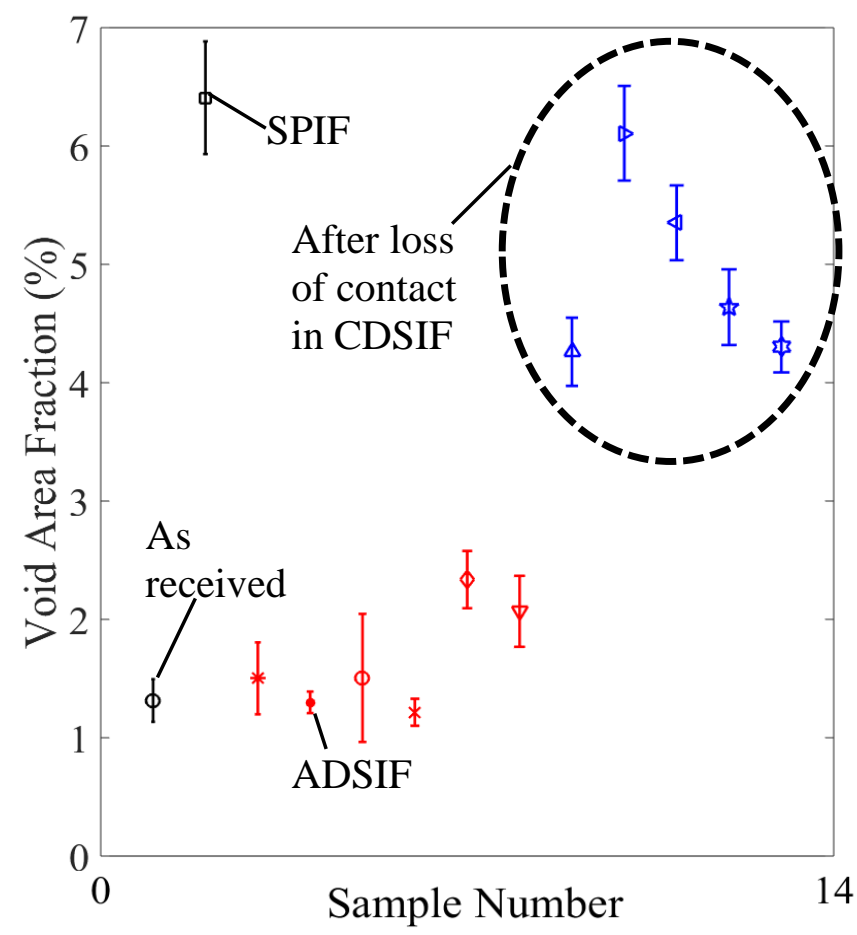

- As Received PVC

- $60^{\circ}$ Cone, SPIF, $\Delta=1.8 \mathrm{~mm}$

* $60^{\circ}$ Cone, CDSIF, $\Delta z=1.8 \mathrm{~mm}, \mathrm{~s}=1.0$

- $60^{\circ}$ Cone, ADSIF, $\Delta \mathrm{z}=1.8 \mathrm{~mm}, \mathrm{~s}=1.0$

- $60^{\circ}$ Cone, CDSIF, $\Delta \mathrm{z}=1.2 \mathrm{~mm}, \mathrm{~s}=1.0$

$\times 60^{\circ}$ Cone, CDSIF, $\Delta \mathrm{z}=1.8 \mathrm{~mm}, \mathrm{~s}=0.8$

$\diamond$ Funnel Rf $=150 \mathrm{~mm}, C D S I F, \Delta z=1.2 \mathrm{~mm}, \mathrm{~s}=0.8$

$\nabla$ Funnel Rf $=80 \mathrm{~mm}, C D S I F, \Delta z=1.2 \mathrm{~mm}, \mathrm{~s}=0.8$

$\Delta 60^{\circ}$ Cone, CDSIF, $\Delta z=1.8 \mathrm{~mm}, \mathrm{~s}=1.0$ (after loss of contact)

$\triangleright 60^{\circ}$ Cone, CDSIF, $\Delta \mathrm{z}=1.2 \mathrm{~mm}, \mathrm{~s}=1.0$ (after loss of contact)

$\triangle 60^{\circ}$ Cone, CDSIF, $\Delta \mathrm{z}=1.8 \mathrm{~mm}, \mathrm{~s}=0.8$ (after loss of contact)

Funnel Rf=150 mm, CDSIF, $\Delta z=1.2 \mathrm{~mm}, s=0.8$ (after loss of contact)

Funnel Rf $=80 \mathrm{~mm}, C D S I F, \Delta z=1.2 \mathrm{~mm}, s=0.8$ (after loss of contact)

14

(f)

Fig. 4: Representative SEM images of (a) as received PVC; and PVC formed with (b) SPIF (c) CDSIF at $\Delta z=1.8 \mathrm{~mm}$ and $s=1.0$ before loss of tool-sheet contact (d) CDSIF at $\Delta z=1.8 \mathrm{~mm}$ and $s=1.0$ after loss of tool-sheet contact (e) ADSIF at $\Delta z=1.8 \mathrm{~mm}$ and $s=1.0$; (f) Void area fraction calculated from SEM images. 


\section{Discussion and Conclusions}

The experimental work performed here demonstrates, for the first time, the feasibility of polymer DSIF. Greater $\Delta z$ and reduction in $s$ result in greater formability in CDSIF.

Furthermore, ADSIF has even greater formability than CDSIF. Key advantages of polymer DSIF over SPIF include greater formability, less void growth in the material and reduction in unwanted bending of the sheet outside the desired forming zone. Given the past work in polymer SPIF and the observations from this work, it is expected that the above advantages of DSIF can be extended to other thermoplastic polymers as well. At the same time, more research is needed to identify the production batch size at which polymer incremental forming is economically and

energetically competitive with hot forming and injection molding. Past work in polymer SPIF [14] has shown that even at a tool feed rate of $50 \mathrm{~mm} / \mathrm{sec}$ (compared to $10 \mathrm{~mm} / \mathrm{sec}$ used here) the PVC sheet does not reach glass transition temperature. While the use of a second tool in DSIF adds a second source of frictional heat generation as compared to SPIF, given the significantly higher thermal conductivity of the metallic tool as compared to the polymer, it is likely that this additional heat will have a minimal effect on increasing the polymer temperature during DSIF. The temperature of the polymer during DSIF needs to be measured to confirm this hypothesis. There is also a need to identify the mechanisms behind the influence of $\Delta z$ and $s$ on formability and geometric accuracy, and for techniques to prevent loss of contact between the sheet and the bottom tool during forming in polymer CDSIF [19].

\section{Acknowledgements}

The authors at Oregon State University acknowledged the financial support provided for this work by the Walmart Manufacturing Innovation Fund. The authors at Northwestern University acknowledged the support from the U.S. Department of Energy (Award No. DEEE0005764).

\section{References}

[1] Malhotra, R., Reddy, N. V.,Cao, J., Automatic 3D Spiral Toolpath Generation for Single Point Incremental Forming, Journal of Manufacturing Science and Engineering, 2010, 132(6), pp. 061003-061013.

[2] Rauch, M., Hascoet, J.-Y., Hamann, J.-C.,Plenel, Y., Tool path programming optimization for incremental sheet forming applications, Computer-Aided Design, 2009, 41(12), pp. 877-885.

[3] Attanasio, A., Ceretti, E.,Giardini, C., Optimization of tool path in two points incremental forming, Journal of Materials Processing Technology, 2006, 177(1-3), pp. 409-412.

[4] Attanasio, A., Ceretti, E., Giardini, C.,Mazzoni, L., Asymmetric two points incremental forming: Improving surface quality and geometric accuracy by tool path optimization, Journal of Materials Processing Technology, 2008, 197(1-3), pp. 59-67.

[5] Zhang, Z., Ren, H., Xu, R., Moser, N., Smith, J., Ndip-Agbor, E., et al., A Mixed DoubleSided Incremental Forming Toolpath Strategy for Improved Geometric Accuracy, Journal of Manufacturing Science and Engineering, 2015, 137(5), pp. 051007-051007.

[6] Xu, R., Shi, X., Xu, D., Malhotra, R.,Cao, J., A preliminary study on the fatigue behavior of sheet metal parts formed with accumulative-double-sided incremental forming, Manufacturing Letters, 2014, 2(1), pp. 8-11. 
[7] Moser, N., Ndip-Agbor, E., Ren, H. Q., Zhang, Z. X., Ehmann, K.,Cao, J., Challenges and Process Strategies Concerning Multi-Pass Double Sided Incremental Forming Key Engineering Materials, 2015, 651-653, pp. 1122-1127.

[8] Malhotra, R., Cao, J., Beltran, M., Xu, D., Magargee, J., Kiridena, V., et al., AccumulativeDSIF strategy for enhancing process capabilities in incremental forming, CIRP Annals Manufacturing Technology, 2012, 61(1), pp. 251-254.

[9] Franzen, V., Kwiatkowski, L., Martins, P. A. F.,Tekkaya, A. E., Single point incremental forming of PVC, Journal of Materials Processing Technology, 2009, 209(1), pp. 462-469.

[10] Franzen, V., Kwiatkowski, L., Neves, J., Martins, P. A. F.,Tekkaya, A. E., 2008, "On the Capability of Single Point Incremental Forming for Manufacturing PVC Sheet Parts," ICTP2008, th International Conference on Technology of PlasticityGyeongju, Korea.

[11] Marques, T., Silva, M.,Martins, P. A. F., On the potential of single point incremental forming of sheet polymer parts, Int J Adv Manuf Technol, 2012, 60(1-4), pp. 75-86.

[12] Martins, P. A. F., Kwiatkowski, L., Franzen, V., Tekkaya, A. E.,Kleiner, M., Single point incremental forming of polymers, CIRP Annals - Manufacturing Technology, 2009, 58(1), pp. 229-232.

[13] Silva, M. B., Alves, L. M.,Martins, P. A. F., Single point incremental forming of PVC: Experimental findings and theoretical interpretation, European Journal of Mechanics - A/Solids, 2010, 29(4), pp. 557-566.

[14] Bagudanch, I., Garcia-Romeu, M. L., Centeno, G., Elías-Zúñiga, A.,Ciurana, J., Forming force and temperature effects on single point incremental forming of polyvinylchloride, Journal of Materials Processing Technology, 2015, 219, pp. 221-229.

[15] Davarpanah, M. A., Mirkouei, A., Yu, X., Malhotra, R.,Pilla, S., Effects of incremental depth and tool rotation on failure modes and microstructural properties in Single Point Incremental Forming of polymers, Journal of Materials Processing Technology, 2015, 222, pp. 287-230.

[16] Digges, K. H., Gann, R. G., Grayson, S. J., Hirschler, M. M., Lyon, R. E., Purser, D. A., et al., Human survivability in motor vehicle fires, Fire and Materials, 2008, 32(4), pp. 249-258.

[17] United States National Research Council, 1979, "Elements of Polymer Fire Safety and Guide to the Designer: Report," National Academies.

[18] Malhotra, R., Cao, J., Ren, F., Kiridena, V., Cedric Xia, Z.,Reddy, N. V., Improvement of Geometric Accuracy in Incremental Forming by Using a Squeezing Toolpath Strategy With Two Forming Tools, Journal of Manufacturing Science and Engineering, 2011, 133(6), pp. 061019061019.

[19] Moser, N., Zhang, Z., Ren, H., Zhang, H., Shi, Y., Ndip-Agbor, E., et al., Effective forming strategy for double-sided incremental forming consideringin-plane curvature and tool direction, CIRP Annals Manuf. Tech., 2016, 60(1). 